dr. Roatiş Marius Dinu, medic specialist chirurgie plastică microchirurgie reconstructivă, Secția Chirurgie Plastică, Spitalul Județean de Urgență Satu Mare

\title{
Sumar
}

Este descris un lambou nasolabial modificat pentru reconstrucția simultană a defectului de aripă nazală şi a zonei perialare după îndepărtarea unui carcinoma bazocelular ulcerat ce interesează zonele amintite. Corpul lamboului este avansat pentru reconstrucția zonei perialare şi a aripii nazale, iar o extensie a lamboului este utilizată pentru a asigura „căptuşeala” aripii nazale.

Cuvinte cheie: lambou nazolabial, perialar, aripa nazală

Cancerul cutanat ce se dezvoltă la nivelul aripii nazale interesează de obicei partea lateral a acesteia şi zona în formă de „C” perialară.

Reconstrucția defectului în această zonă este destul de dificilă având în vedere faptul că este o zonă de confluență a mai multor unități estetice ale feței: tegumentul buzei superioare, a porțiunii mediale a obrazului, a nasului şi şanțul melolabial. De obicei defectul combinat al acestei zone este reconstruit prin utilizarea unui lambou şi a grefei cutanate. Însă utilizarea grefei cutanate pentru zonele cu defect profund conduce la un rezultat estetic nesatisfăcător.

\section{Prezentare de caz}

Pacientă de 82 ani este internată în secția Chirurgie Plastică a Spitalului Județean de Urgență Satu Mare, prezentînd un carcinom ulcerat (fig.1) ce interesează aripa nazală dreaptă şi zona perialară de aceeaşi parte. Operația s-a efectuat în anestezie locală cu xilină $1 \%$ datorită afecțiunilor associate. După excizia formațiunii tumorale cu o margine de siguranță de peste $5 \mathrm{~mm}$, defectul rămas a fost de aproximativ de $5 \mathrm{~cm} / 3 \mathrm{~cm}$ (fig.2) şi a fost reconstruit cu un lambou nasolabial modificat, realizându-se reconstrucția simultană atât a aripi nazale drepte cât şi a zonei perialare homolaterale.

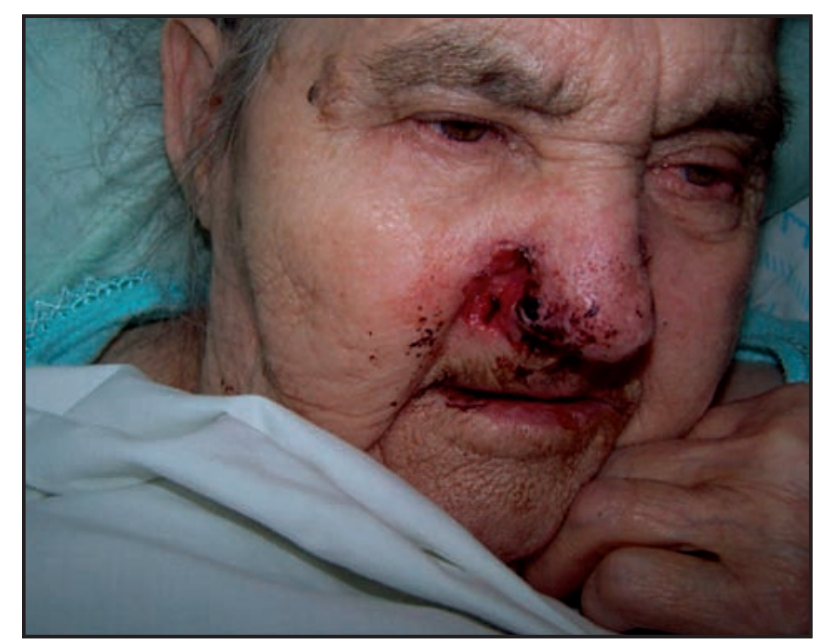

Fig.1 Femeie de 82 ani prezentând un carcinom bazocelular confluent ce interesează aripa nazală şi zona perialară dreaptă 


\section{Tehnica operatorie}

Lamboul utilizat este în esență un lambou nazolabial de avansare în V-Y croit pe obrazul drept, ce prezintă către extremitatea sa o prelungire ce este utilizată pentru a căptuşi fața internă a aripii nazale (fig.4). Incizia interesează straturile pielii până la țesutul subcutanat şi lamboul se avansează în maniera V-Y pentru a reconstrui defectul de aripă nazală şi cel perialar. Sursele de vascularizație ale lamboului sunt perforantele musculocutanate din artera facială, artera infraorbitală şi transversă a feței (fig.3). Porțiunea „in extenso” a lamboului este utilizată pentru a căptuşi partea internă a aripii nazale prin răsturnare.

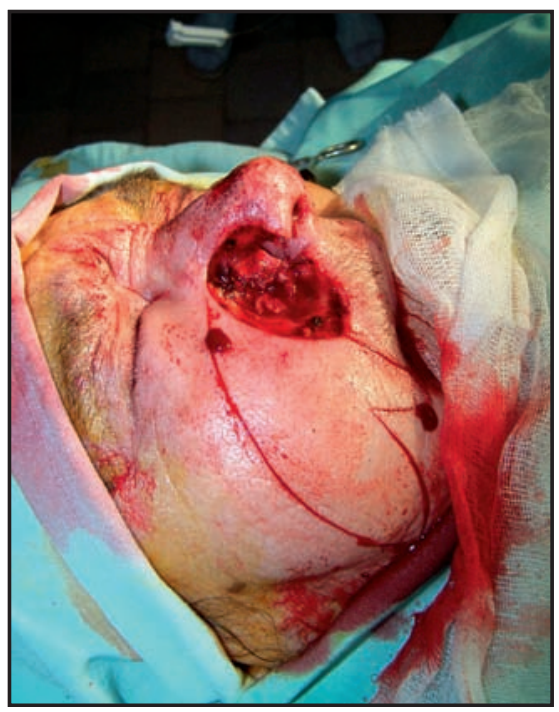

Fig.2 Defectul rămas după excizia tumorii interesând aripa nazală dreaptă, zona perialară şi tegumentul nasului. De asemenea se observă desenul lamboului ce este utilizat pentru acoperirea defectului astfel creat.

Fig.3 Sursa de vascularizație a lamboului: artera facial, artera transversă a feței şi artera infraorbitară. (A combined V-Y advancement-turnover flap for simultaneous perialar and alar reconstruction-D. L. Feinendegen, M. Langer and D. Gault)

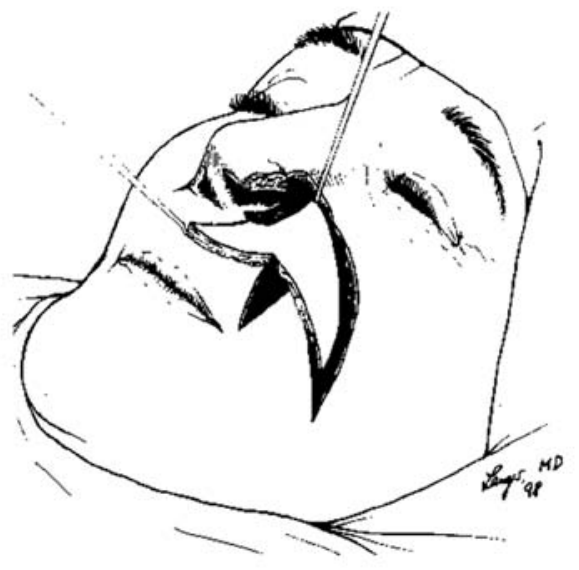

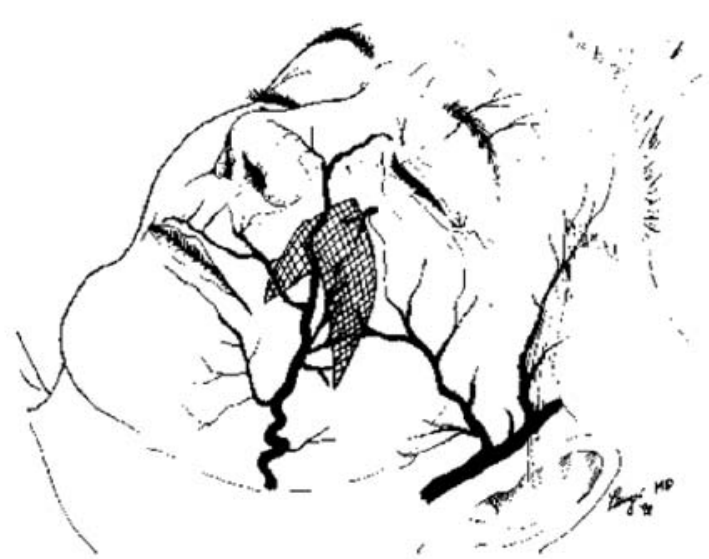

Fig.4 Lamboul în V-Y din zona obrazului combinat cu lamboul răsturnat din regiunea nazolabială. (A combined V-Y advancement-turnover flap for simultaneous perialar and alar reconstruction-D. L. Feinendegen, M. Langer and D. Gault) 


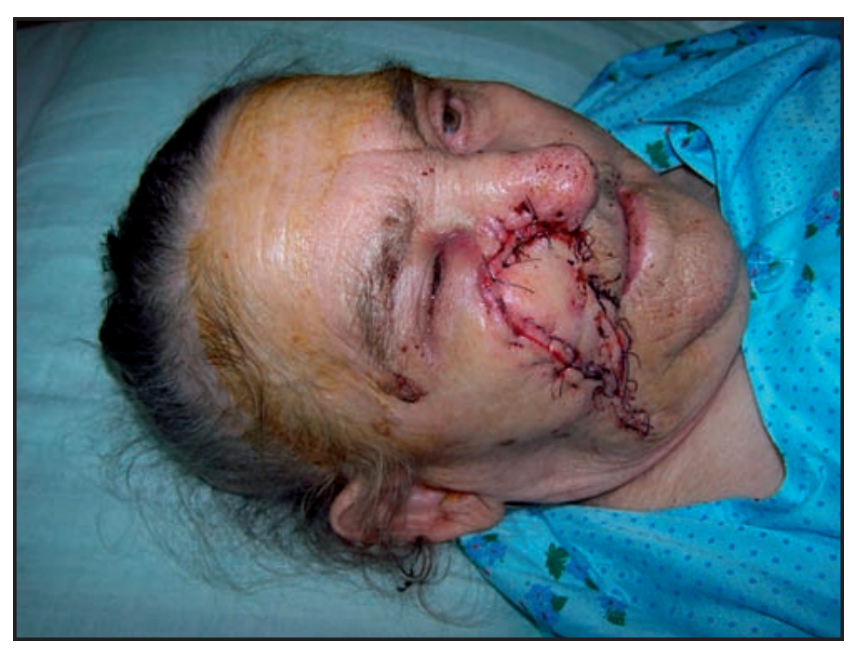

Fig.5 Rezultat la 2 zile postoperator
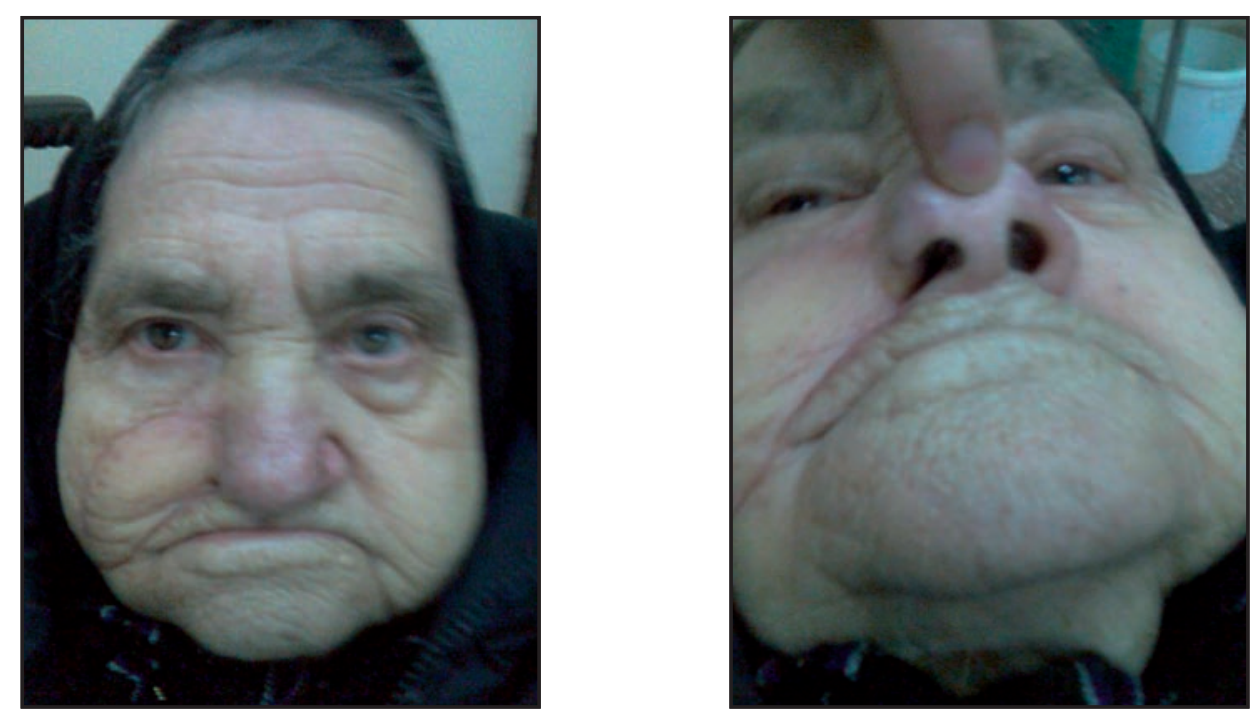

Fig. 6 Rezultatul la 3 luni postoperator

\section{Discuții}

Datorită vascularizației bogate la nivelul plexului subdermal de la nivelul feței lamboul descris mai sus permite reconstrucția aripii nazale atât la exterior cât şi la interior prin posibilitatea răsturnării lamboului nazolabial. La persoanele în vârstă datorită laxității cutanate, avansarea lambourilor cutanate ale obrazului este făcută cu uşurință, spre deosebire de persoanele tinere unde elasticitatea cutanată este mai mare. Deoarece lamboul care se avansează duce tegument din regiunea obrazului care este bogat în pilozitate acest lambou nu poate fi utilizat la bărbați. Deoarece cicatricile postoperatorii sunt ascunse în pliurile şi şanțurile cutanate ale feței şi faptului că lambourile sunt din imediata vecinătate, rezultatul estetic pe lîngă cel funcțional este foarte bun (fig.6).

\section{Bibliografie}

1. D. L. Feinendegen, M. Langer and D. Gault: A combined V-Y advancement-turnover flap for simultaneous perialar and alar reconstruction, British Journal of Plastic Surgery (2000), 53, 248-250, The British Association of Plastic Surgeons DOI:10.1054/bjps.2000.3326 
2. Joseph Cvancara, and J. Michael Wentzell: Shark Island Pedicle Flap for Repair of Combined Nasal AlaPerialar Defects, 2006 by the American Society for Dermatologic Surgery, Inc. Published by Blackwell Publishing, ISSN: 1076-0512 Dermatol Surg 2006; 32:726-729 DOI: 10.1111/j.15244725.2006.32146x

3. V. Cervelli, Pietro Gentile, Davide J. Bottini, Giuseppe M. Dasero: Reconstruction of the Nasal Alar, Brief clinical notes- The Journal of Craniofacial Surgery, volume 18, number 6, november 2007

4. Valerio Cervelli, Pietro Gentile, Davide Johan Bottini: Reconstruction of the Alar Nose, Brief clinical notesThe Journal of Craniofacial Surgery, volume 18, number 6, november 2007 